\title{
A case of small-bowel perforation caused by a migrated duodenal stent
}

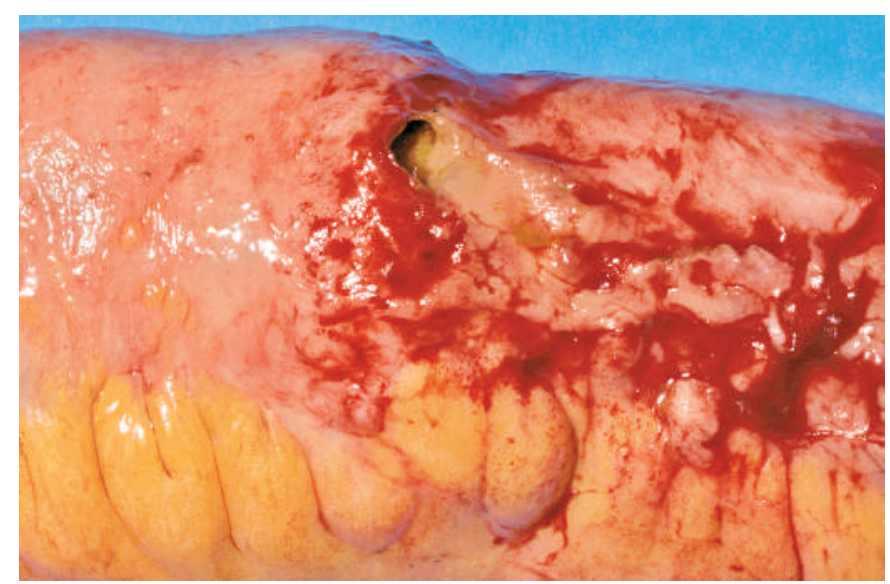

Figure 1 Section of ileum showing perforation (stent removed).

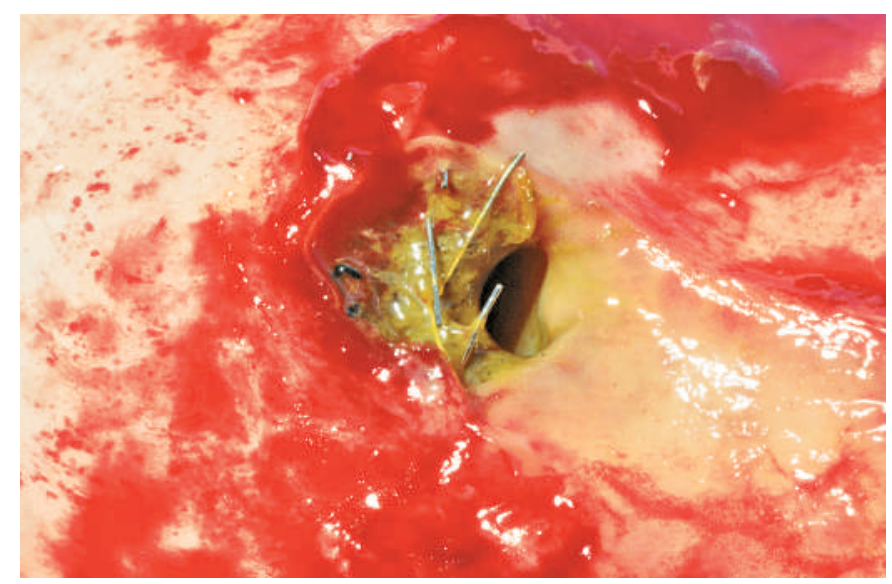

Figure 2 Close up with stent in situ. The metallic stent had been placed endoscopically for gastric outlet obstruction secondary to a pancreatic lesion. The lesion was most probably inflammatory and when it resolved the stent migrated causing perforation of the distal ileum.

Metal stents are used to palliate advanced malignant gastric outlet and duodenal obstruction [1,2]. We present a rare complication due to a migrated duodenal stent, that highlights the need for a diagnosis of malignancy before deployment.

A 73-year-old man developed symptoms of gastric outlet obstruction following lumbar spine laminectomy at another institution. Computed tomography (CT) scanning revealed a mass lesion arising from the head of the pancreas compressing the second part of the duodenum. A presumptive diagnosis of carcinoma of the pancreas was made and an expanding metal stent was deployed without a histological diagnosis.

One month later he presented to our hospital with vague abdominal pain. A further CT scan showed free air and fluid within the peritoneal cavity and the pancreas looked normal. At laparotomy he was found to have a perforation where the metal stent had impacted in the distal ileum (Figure $\mathbf{1}$ and 2). The pancreas felt normal. It was concluded that the pancreatic mass previously seen on CT scanning was inflammatory, and that as it resolved the stent had migrated. A small-bowel resection was performed. Following a good initial recovery the patient later developed cardiovascular instability from acute bacterial endocarditis (diagnosed on echocardiography) which was fatal. An autopsy was not performed as a cause of death had been identified.

Duodenal perforation is a recognized complication associated with metal stents, both those in situ and migrated esophageal devices [3-5]. There have however been no reported cases of a duo- denal stent migrating into the distal ileum and causing perforation. This case demonstrates the importance of a definitive diagnosis of malignancy before placing a stent for palliation.

\section{Endoscopy_UCTN_Code_CPL_1AH_2AD}

P. W. Moxey, A. Z. Khan, N. D. Karanjia

Department of Surgery, Royal Surrey

County Hospital, Guildford, UK.

\section{References}

${ }^{1}$ Feretis C, Benakis P, Dimopoulos C. Palliation of malignant gastric outlet obstruction with self-expanding metal stents. Endoscopy 1996; 28: $225-228$

2 Jung G, Song H, Kang $\mathrm{S}$ et al. Malignant gastroduodenal obstructions: treatment by means of a covered expandable metallic stent - initial experience. Radiology 2000; 216: $758-763$

${ }^{3}$ Bessoud B, De Baere T, Denys A et al. Metallic stents for malignant gastroduodenal obstruction. J Vasc Interv Radiol 2005; 16: 247-253

${ }^{4}$ Thumbe V, Houghton A, Smith S. Duodenal perforation by a Wallstent. Endoscopy 2000; 32: 495-497

${ }^{5} \mathrm{Kim}$ H, Han J, Kim T et al. Duodenal perforation as a delayed complication of placement of an oesophageal stent. J Vasc Interv Radiol 2000; 11: $902-904$

\section{Corresponding author}

\section{N. D. Karanjia, M.D.}

Royal Surrey County Hospital

Guildford

Surrey, GU2 7XX

UK

Fax: $\quad+44-1483-402740$

Email: Nariman.Karanjia@ ntlworld.com 